\title{
CORRESPONDENCE AND COMMUNICATION
}

\section{Laser-guided plastic surgery}

Plastic surgery relies on accurate preoperative evaluation and planning. The simple marker pen and tape measure have been essential tools of the trade, but modern tradesmen in engineering and other fields have moved on to more sophisticated devices. One such device is a laser level that emits a laser line (as opposed to a single dot), which can be orientated with the help of an incorporated spirit level (Figures 1 and 2). The ubiquitous nature of such pocket devices allows these to be purchased from a local hardware store at a price equivalent to that of a few good marker pens and a tape measure. Some of these devices also come with a built-in tape measure. The devices shown are low-power $(1 \mathrm{~mW})$ class II lasers similar to that found in laser pointers.

We have found these devices to be excellent tools for marking patients prior to surgery. Examples include alignment for nipple positioning prior to nipple reconstruction, positioning of a neo-umbilicus during abdominoplasty or autologous breast reconstruction using abdominal tissue and for marking the midline and other points prior to breast reduction. Numerous other applications also exist, especially in a research setting to obtain accurate data regarding aspects of symmetry or alignment in many areas of the body. Figures 3 and 4 are examples of the laser line in use.

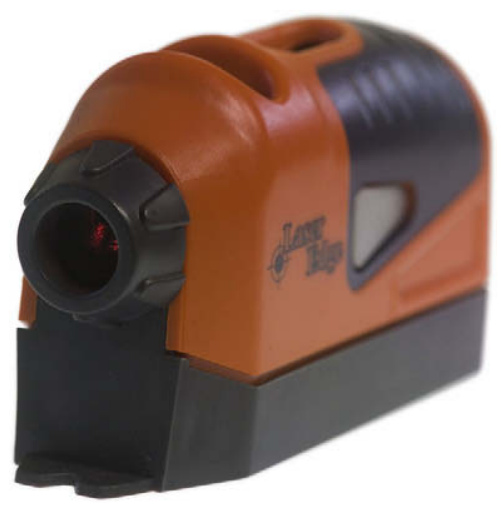

Figure 1 Single-beam laser level with dual spirit levels.

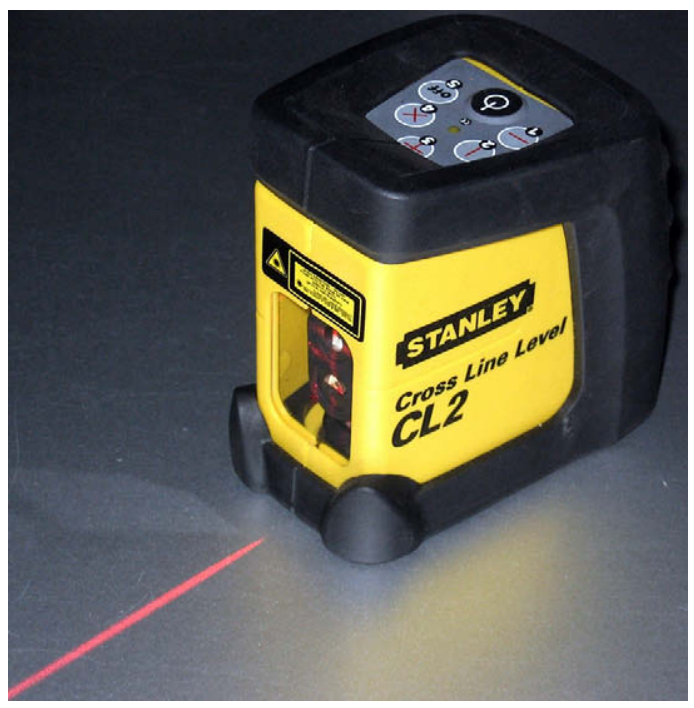

Figure 2 Cross-hair laser level.

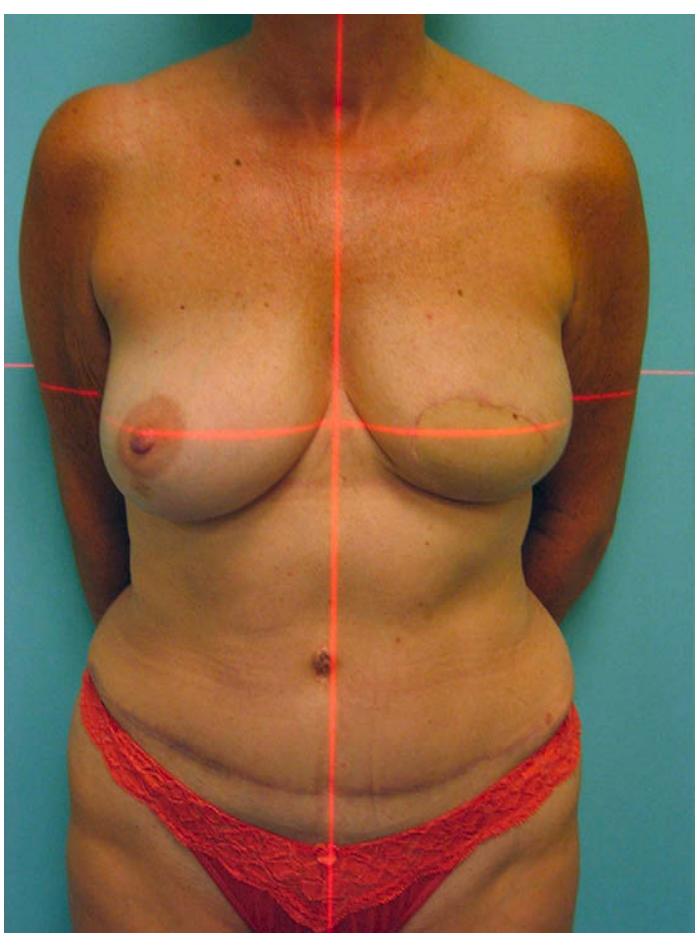

Figure 3 Marking for nipple positioning.

1748-6815/\$ - see front matter @ 2008 British Association of Plastic, Reconstructive and Aesthetic Surgeons. Published by Elsevier Ltd. All rights reserved. doi:10.1016/j.bjps.2008.08.048 


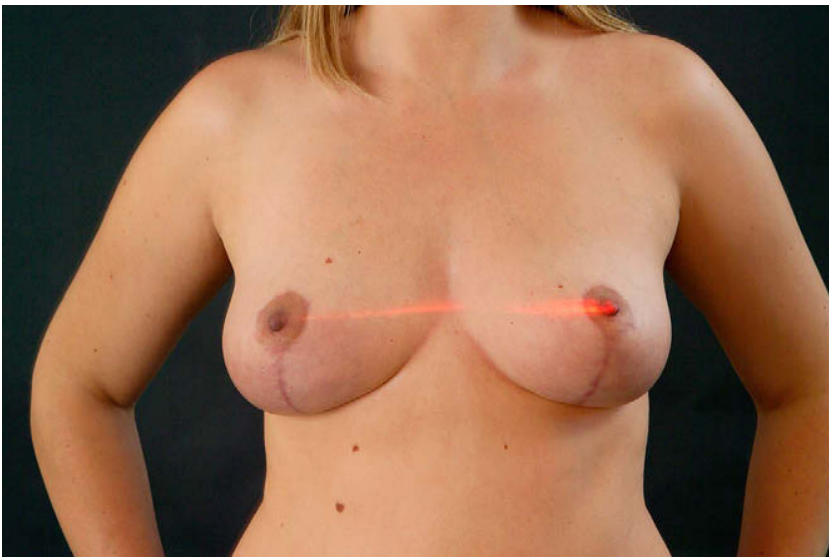

Figure 4 Demonstrating nipple symmetry.

These simple and cheap devices can assist in providing accurate measurements and reduce the need for excessive pen markings (dot-to-dot pen marking is redundant) whilst avoiding direct skin contact and can, therefore, be used intra-operatively if required. ${ }^{1}$
Of course, the device must not be used around the eyes, and if used intra-operatively during general anaesthesia, the eyes should be - and will usually already be - taped shut by the anaesthetist. As with any laser pointer, users must be careful about where the laser is pointing.

\section{Acknowledgement}

Mr Dean Boyce MD FRCS FRCS(Ed) FRCS(Plast), Consultant Plastic Surgeon, Welsh Centre for Burns and Plastic Surgery - operating surgeon for the patient in Figure 3.

\section{Reference}

1. Tadiparthi $\mathrm{S}$, Shokrollahi $\mathrm{K}$, Juma A, et al. Using marker pens on patients: a potential source of cross infection with MRSA. Ann $R$ Coll Surg Engl 2007 Oct;89:661-4.

Kayvan Shokrollahi Phillip Blondeel Morriston, Swansea SA6 6NL, United Kingdom E-mail address: kshokrollahi@hotmail.com 